\title{
Reply to "Accurate measurement of the normality values of macroaggregated albumin lung perfusion scan in hepatopulmonary syndrome'
}

\author{
Andréa Simone Siqueira de Queirós ${ }^{1}$
}

Received: 30 June 2015/ Accepted: 5 July 2015 / Published online: 21 July 2015

(C) The Japanese Society of Nuclear Medicine 2015

Dear Editor,

It is with great interest that we reply to the letter of questions and comments of Dr. Prof. Xiao Li to the article "Evaluation of normality and reproducibility parameters of ${ }^{99 m}$ Tc-MAA scintigraphy in the diagnosis of intrapulmonary vascular dilatations". However, we do not agree with the criticism regarding the group evaluated and the protocol used for scintigraphy with technetium-99 m-labeled macroaggregated albumin ( $\left.{ }^{99 \mathrm{~m}} \mathrm{Tc}-\mathrm{MAA}\right)$.

Our aim was to assess normal values for scintigraphy with ${ }^{99 \mathrm{~m}} \mathrm{Tc}-\mathrm{MAA}$ and not to compare scintigraphic findings among patients with hepatosplenic schistosomiasis and normal subjects. So we chose, as the group to be assessed, individuals without liver, heart or lung diseases, previously excluded by clinical, echocardiographic and abdomen ultrasound assessment.

The second point to be discussed is the time of image acquisition, considered too long. In the literature, the time between intravenous injection of ${ }^{99 \mathrm{~m}} \mathrm{Tc}-\mathrm{MAA}$ and the acquisition of images has varied from acquisition immediately after injection of the radiopharmaceutical to $60 \mathrm{~min}$ [1-3]. The passage of ${ }^{99 \mathrm{~m}} \mathrm{Tc}-\mathrm{MAA}$ from pulmonary capillaries to the systemic circulation is not immediate in intrapulmonary vascular dilatation, and so we believe that the interval between injection of ${ }^{99 \mathrm{~m}} \mathrm{Tc}-\mathrm{MAA}$ and the

This reply refers to the article available at doi:10.1007/s12149-0151001-7.

Andréa Simone Siqueira de Queirós

andrasq@ hotmail.com

1 Universidade Federal de Pernambuco, Av. Prof. Moraes Rego

s/n, Cidade Universitária, Recife-PE, Recife,

Pernambuco CEP 50670-901, Brazil image acquisition is important to increase the test sensitivity.

In the discussion of our article, we consider that the use of different methodologies in the performance of tests for the analysis of control groups can be the cause of differences and we draw attention to the lack of a standard protocol for the performance of scintigraphy with ${ }^{99 \mathrm{~m}} \mathrm{Tc}$ MAA in pulmonary vascular dilatation studies.

Best regards,

Andrea Simone Siqueira de Queiros

\section{References}

1. Abrams G, Jaffe C, Hoffer P, Binder H, Fallon MB. Diagnostic utility of contrast echocardiography and lung perfusion scan in patients with hepatopulmonary syndrome. Gastroenterology. 1995;109:1283-8.

2. Krowka MJ, Wiseman GA, Burnett OL, Spivey JR, Therneau T, Porayko MK, et al. Hepatopulmonary syndrome: a prospective study of relationships between severity of liver disease, $\mathrm{PaO}(2)$ response to $100 \%$ oxygen, and brain uptake after (99m)Tc MAA lung scanning. Chest. 2000;118(3):615-24.

3. Hosono M, Machida K, Honda N, Takahashi T, Kashimada A, Osada $\mathrm{H}$, et al. Quantitative lung perfusion scintigraphy and detection of intrapulmonary shunt in liver cirrhosis. Ann Nucl Med. 2002;16(8):577-81. 